\title{
The Effect of Visual Structure of Pictorial Metaphors on Advertisement Attitudes
}

\author{
Shuo Cao ${ }^{1,2}$, Huili $\mathrm{Wang}^{2} \&$ Xiaoxia Zou ${ }^{2}$ \\ ${ }^{1}$ Faculty of Management and Economics, Dalian University of Technology, Dalian, China \\ ${ }^{2}$ School of Foreign Language, Dalian University of Technology, Dalian, China \\ Correspondence: Xiaoxia Zou, 2\#, linggong Road, Ganjingzi District, Dalian 116024, Liaoning, China.
}

\author{
Received: August 4, 2018 Accepted: October 29, 2018 Online Published: November 24, 2018 \\ doi:10.5539/ijms.v10n4p60 URL: https://doi.org/10.5539/ijms.v10n4p60
}

\begin{abstract}
With the development of the economy, the advertising industry has also flourished, and visual metaphors have been frequently used in advertising. Through the use of visual metaphor, advertisers are eager to give consumers a deep impression, and the ultimate goal is to sell the products in the ads. Previous visual metaphor research has contributes more to understand the needs of consumers better, and offered advertisers some guidance in the advertising design. The current study works on the liking degree of people of different backgrounds toward the ads using visual metaphor of hybrid structure. This study takes 101 Chinese college students as participants to measure the extent to which they appreciate the ads using visual metaphors. 20 sets of ad pictures, covering a wide range of products, categorized conceptually and perceptually, are tested in terms of ad liking, elaboration, and comprehension. The results indicate that the visual pictures that have both similar functions and shapes rank top in all the perspectives examined, followed by those having dissimilar shape and similar function and those having similar shape and dissimilar function. The visual pictures that are dissimilar both in shape and in function are least favored. In addition, demographical analysis was performed, showing a higher appreciation for the ad visual metaphors among participants of bachelor's degree and master's degree, females and younger generation. Moreover, the findings, with specific marketing implication for designing and managing visual metaphors in ads, are very valuable for marketers who target at college students.
\end{abstract}

Keywords: advertisement attitude, customers, visual metaphor

\section{Introduction}

Along with the development of advertising industry, visual metaphors are frequently used in ads. By using visual metaphor, advertisers are eager to give a deep impression on customers in order to sell the products advertised in the ad. Metaphors may enhance attention to an advertisement (Goodstein, 1993; McGuire, 2000), increase the believability of an advertisement (Lee \& Olshavsky, 1995; McGuire, 2000; Toncar \& Munch, 2001; McQuarrie \& Phillips, 2005), and increase the amount of information a consumer remembers (Greenwald \& Leavitt, 1984). In addition, metaphoric advertisements can elevate a consumer's mood (Heckler \& Childers, 1992; McQuarrie \& Mick, 1996; McGuire, 2000). For example, the presence of metaphors has shown to elicit affective responses (such as a sense of accomplishment) at successfully deciphering the intended meaning or lead to a positive impression of a brand or product (Laird, 1974; Krugman, 1983; Toncar \& Munch, 2001).

Compared with linguistic metaphor, visual metaphor is developed in recent ten years. It is mainly about the classification of visual metaphors. The extant literature related to visual metaphors in marketing and advertising report two parallel research tracks, including consumers' explicit processing of metaphoric advertisements (Morgan \& Reichert, 1999; Toncar \& Munch, 2001), and implicit processing of metaphoric advertisements (Faust \& Mashal, 2007; Kacinik \& Chiarello, 2007). However, as a newly- studied rhetoric mode, the visual metaphor needs to be further explored in terms of visual structure, social context and persuading effect. The purpose of this research is to analyze the most common visual structure-hybrid visual metaphor (the hybrid of target domain object and source domain object). In the case of perceptual and conceptual features, this paper studies the attitude of customers with different background to visual metaphor in the ads.

Clearly structured, the paper has several sections: abstract, introduction, literature review, methodology, the results and the discussion, the conclusions, the references, the appendices, and the acknowledgement. 


\section{Literature Review}

Visual metaphor is a kind of rhetorical figure that expresses visual ideas. As a unique speech way, it expresses an artful representation. Visual metaphor can be achieved by choosing, organizing, and controlling visual elements. These tasks include creators' ideas, which are very complicated ways of expression, such as choosing the visual elements that are related to the topic, organizing these element constitute forms, controlling their sequences and contrasting the foreground with the background, all for the purpose of ad viewer's being able to infer the theme.

\subsection{Perceptual and Conceptual Similarity}

There has been many advantageous effect of using visual metaphors in ads. Of all the influences, the most discussed is the extent to which viewers can understand and appreciate the visual metaphors. Take the ad picture (Figure 1) for a car for instance. The car (target) is delineated like a red pepper (source). Retrieving from the common sense and knowledge, viewers of the advertisement will understand the two items are in same shape, which is stereotypically consistent. For another example (Figure 2), a pesticide is visually presented as a frog. Between the pesticide (target) and the frog (source), there is a specific relationship, which is generally believed to be that both pesticide and frog kill pests, which means the target and the source share a similar function In the above two cases, according to either the shared shape or the shared function that exist between two visual elements, customers can easily understand and remember the advertisement content, which is known as the power of visual metaphor.

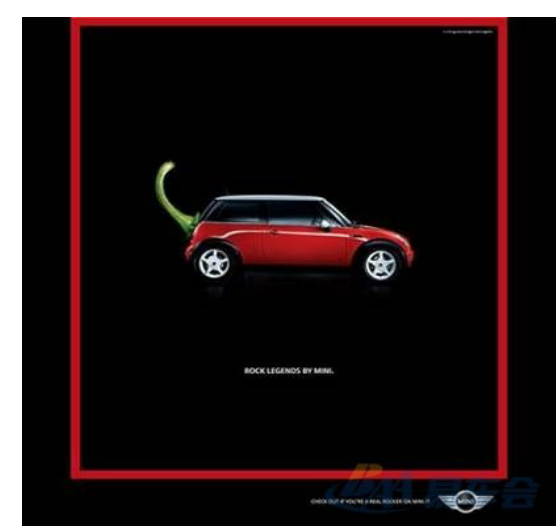

Figure 1

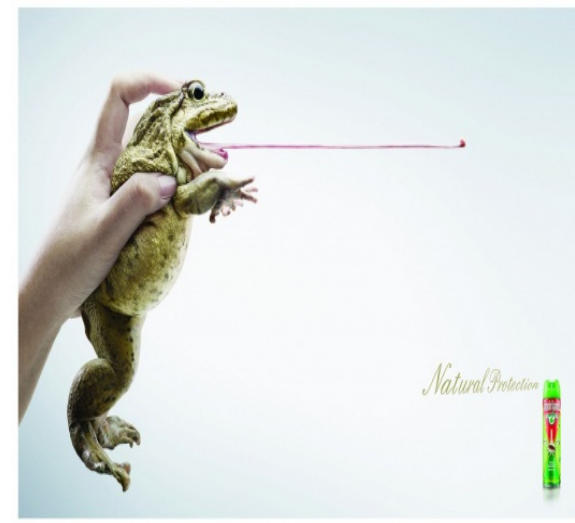

Figure 2

\subsection{Typology of Visual Metaphors}

Besides the perceptual and conceptual elements that should be taken into consideration, visual structure is another important perspective for ad visual metaphor with regard to understanding and appreciation. Visual structure refers to how the two metaphorical objects are physically arranged. Different from verbal metaphor which has been studied sufficiently, for which a systematic frame has been built, visual metaphor has been drawing increasing interest just in the past decade. The related study focused on the typology of visual structure in visual metaphor is shown in the following chart (Table 1): 
Table 1. Summary of three typologies of visual rhetorical figures

Forceville $(1996,2005)$

This typology distinguishes three types of visual metaphors.

\begin{tabular}{ll}
\hline Typology & Description \\
\hline 1.Simile & A visual metaphor in which source and target domains are presented separately. \\
2.Hybrid metaphor & A visual metaphor in which source and target domains are fused. \\
3.Context metaphor & $\begin{array}{l}\text { A visual metaphor in which only one domain (target/source) is } \\
\text { present and the other domain is absent but suggested by the pictorial context. }\end{array}$ \\
\hline
\end{tabular}

Gkiouzepas and Hogg (2011)

This Typology consists of two dimensions: object's mode of representation

and visual scenarios resulting in six $(2 * 3)$ different types of visual rhetorical figures.

\begin{tabular}{|c|c|}
\hline Typology & Description \\
\hline 1.Mode of Representation & It refers to how the two metaphorical objects are arranged. \\
\hline Juxtaposition & The two metaphorical objects are separated from each other. \\
\hline Synthesis & The two metaphorical objects are fused together. \\
\hline 2.Visual Scenarios & It refers to how the two metaphorical objects are constructed in order to be related to each other. \\
\hline Realistic symbiosis & $\begin{array}{l}\text { The two metaphorical objects represent real-life events and are } \\
\text { linked showing unexpected similarities in terms of color, position. or angle of view. }\end{array}$ \\
\hline Replacement & $\begin{array}{l}\text { One of the metaphorical objects is replaced by an object foreign to } \\
\text { the schema. Both metaphorical objects are present in their entirety. }\end{array}$ \\
\hline Artificial symbiosis & $\begin{array}{l}\text { The two metaphorical objects are artificially placed together: visual space } \\
\text { lacking realistic visual background, and other elements, such as the lack of perspective, differences in } \\
\text { position, and size. }\end{array}$ \\
\hline \multicolumn{2}{|c|}{$\begin{array}{l}\text { Phillips and McQuan ie (2004) } \\
\text { This typology consists of two dimensions- meaning operation and } \\
\text { Visual structure resulting in nine }(3 * 3) \text { different types of visual rhetorical figures. }\end{array}$} \\
\hline Typology & Description \\
\hline 1. Meaning operation & $\begin{array}{l}\text { It refers to die target or focus of the cognitive processing required to } \\
\text { comprehend the picture. }\end{array}$ \\
\hline Connection & $\begin{array}{l}\text { The two metaphorical elements are associated with each other in some way. } \\
\text { (A is associated with B). }\end{array}$ \\
\hline Comparison for similarity & The two metaphorical elements are similar in some way. (A is like B). \\
\hline Comparison for opposition & $\begin{array}{l}\text { The two elements are featured in such a way that one is nor like the other. } \\
\text { (A is not like B). }\end{array}$ \\
\hline 2. Visual structure & It refers to how the two metaphorical objects are physically arranged. \\
\hline Juxtaposition & The two metaphorical elements are presented side by side separately. \\
\hline Fusion & The two metaphorical elements are fused together. \\
\hline Replacement & $\begin{array}{l}\text { Of the two metaphorical elements, only one element is present } \\
\text { while the other element is absent. }\end{array}$ \\
\hline
\end{tabular}

Forceville (1996, 2005)'s Typology: This typology distinguishes three types of visual metaphors- Simile, Hybrid metaphor and Context metaphor. Simile is a visual metaphor in which the source and target domains are presented separately while Hybrid Metaphor is one in which source and target domains are fused. Context Metaphor is a visual metaphor in which only one domain (target/source) is present and the other domain is absent and is only suggested by the pictorial context. The reader has to decipher the absent domain based on the domain present in the visual metaphor.

Gkiouzepas and Hogg (2011)'s Framework: This typology consists of two dimensions. The first dimension is the object's mode of representation - whether the two metaphorical objects in the ads are separated (juxtaposition) or fused together (synthesis). The second dimension is the visual scenarios and addresses how the two metaphorical objects are constructed in order to be related to each other. There are three types of visual scenarios: Realistic symbiosis, replacement, and artificial symbiosis.

Phillips and McQuarrie (2004) Typology: The primary argument of Phillips and McQuarrie (2004) is that advertisers select visual elements from a palette which has an internal structure. Although this typology is derived in part from previous taxonomies, such as Forceville (1996), unlike them, this typology predicts several cognitive and emotional responses of consumers to various types of visual rhetorical figures that can be 
empirically tested (Phillips \& McQuarrie, 2004). This typology differentiates visual rhetorical figures along two dimensions. The first dimension is the 'visual structure', which refers to "the way the two elements that comprise the visual rhetorical figure are physically pictured in the ad". The second dimension is 'meaning operation', which "refers to the target or focus of the cognitive processing required to comprehend the picture". Juxtaposition is that the two metaphorical elements are presented side by side separately; Fusion is that the two metaphorical elements are fused together; Replacement is that of the two metaphorical elements, only one element is present.

\subsection{Complexity and Appreciation for Visual Metaphors}

Related to the visual structure depicted by Phillips and McQuarrie (2004), there is also another theory, which represents the relationship between conceptual complexity and appreciation degree in different structure. As is shown in Figure 3, horizontal coordinate represents conceptual complexity, vertical coordinate represents appreciation degree, as is seen, the fusion structures were appreciated more than juxtapositions when they were comprehended. Replacements are thought to be appreciated less than juxtapositions, ads with no metaphor are appreciated least than other three structures, as we can see clearly that fusion gets the highest appreciation.

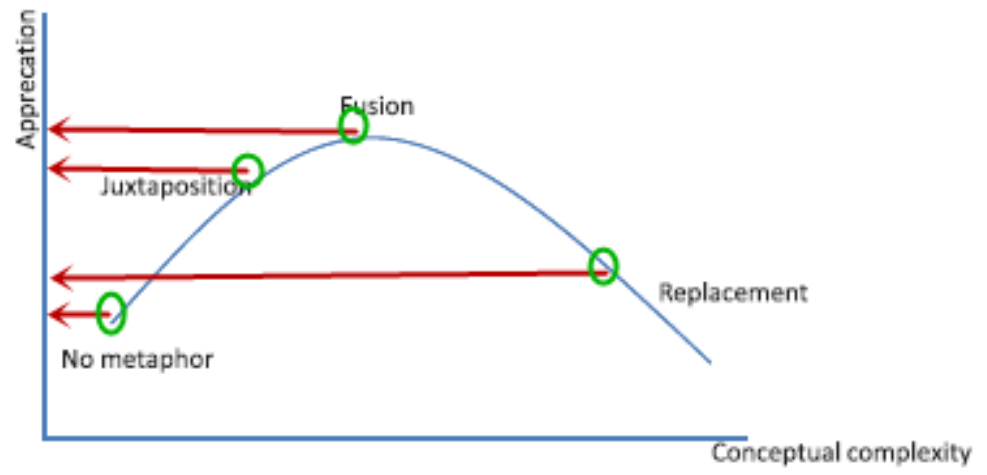

Figure 3. Inverted U-curve

The reasons are as follows:

In juxtaposition structure, the demands on consumers processing the content are the least (Phillips \& McQuarrie, 2004). This is because there are two elements in the ad that are clearly separated. Consumers simply have to discern how the two elements are related.

In fusion structure, the complexity increases because the two elements are merged together and consumers have to disentangle them before they can process the information (Phillips \& McQuarrie, 2004). This increases the demand on consumers' processing.

Replacement structure is the most demanding due to the fact that consumers must discern the missing second element that is related to the element present in the ad and then process how the two elements are related (Phillips \& McQuarrie, 2004). Identifying the missing element and then relating it to the element present requires significantly higher processing efforts compared to either fusion or juxtaposition structures.

As can be seen from the above, the fusion of visual metaphor works best for ad appreciation, and, my study focuses on this situation.

\section{Methods}

Taking Chinese college students as participants, this study uses 20 visual metaphors in advertisement which are categorized perceptually and conceptually, with an intention of finding out answers for three specific research questions: a) whether visual structure of ad metaphors will perceptually and conceptually affect ad liking, elaboration, and comprehension; b) what perceptual and conceptual impact visual structure of ad advertisements will have on ad liking, elaboration, and comprehension; c) to what extent the impact will be.

To achieve these purposes, an online survey questionnaire, based on Phillips \& McQuarrie's paradigm, was designed and delivered to test the perceptual and conceptual influence visual metaphors in ads may have on college customers. (https://www.sojump.com/wjx/manage/myquestionnaires.aspx) 


\section{海宸星}

重要提醒 : 请绑定微信账号，绑定后可通过微信管理问卷、获得新答卷提醒以及找回密码！

+创建问卷、考试、投票

Figure 4. Basic information of the survey

In the process of this research, a questionnaire is designed and distributed. There are three steps in the procedure: Step one: visual material selection

Twenty sets of pictures are chosen out of hundreds, covering a variety of product categories, including foods and drugs, clothing and cosmetics, and even articles for daily use. The chosen pictures are closely related to our daily life and easy to understand. Pilot study proves that every product picture is clearly recognized and well comprehended.

\section{Step two: categorization of visual pictures}

The visual structure of visual metaphor is determined by the features of the target and the source in the picture, mainly focused on shape and function. Accordingly, the pictures are grouped into four conditions:

1. Those having similar shape and similar functions $(\mathrm{S}+\mathrm{F}+)$, for example, there is an advertisement about the eraser as Figure 5:

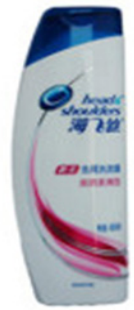

(a)

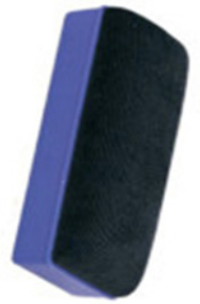

(b)

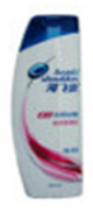

(c)
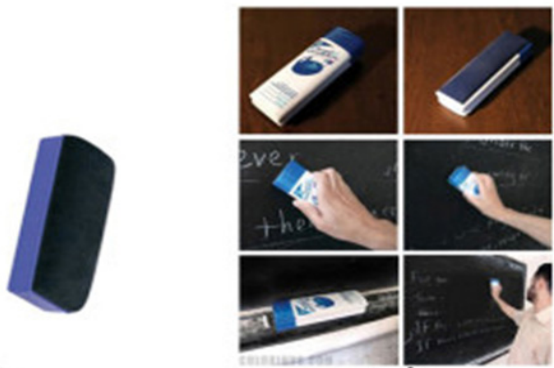

(d)

Figure 5. An example for $(\mathrm{S}+\mathrm{F}+)$

2. Those having similar shape but different functions ( $\mathrm{S}+\mathrm{F}-)$, for example, it is an advertisement about the clothes rack as Figure 6: 


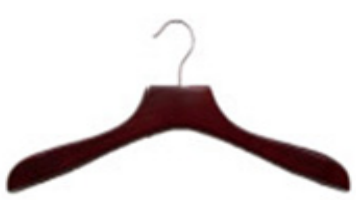

(a)

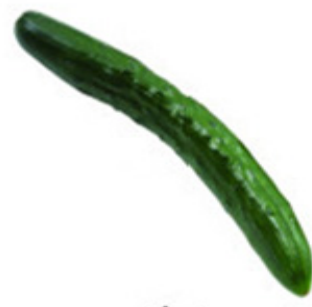

(b)

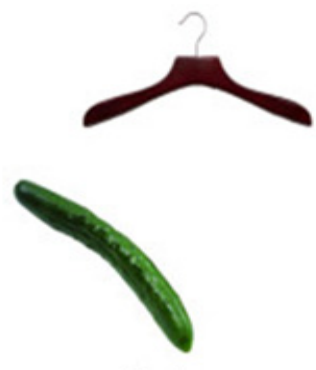

(c)

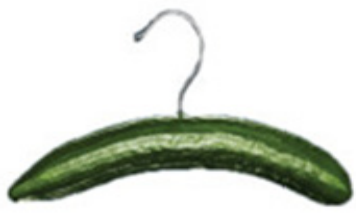

(d)

Figure 6. An example for $(\mathrm{S}+\mathrm{F}-)$

3. Those having different shape but similar functions $(\mathrm{S}-\mathrm{F}+)$, for example, it is an advertisement about the pesticide as Figure 7:

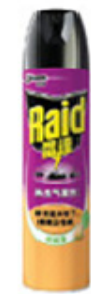

(a)

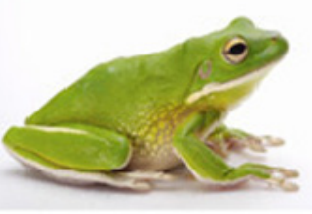

(b)

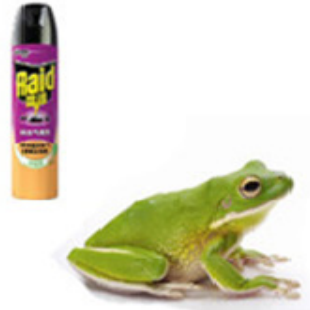

(c)

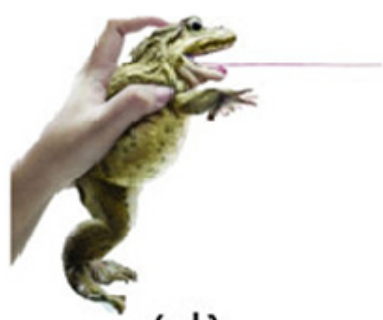

(d)

Figure 7. An example for (S-F+)

4. Those having different shape and different functions (S-F-), for example, there is an advertisement about the earphone as Figure 8:

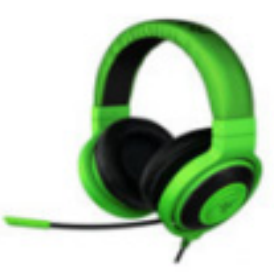

(a)

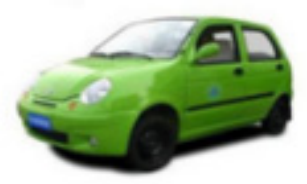

(b)

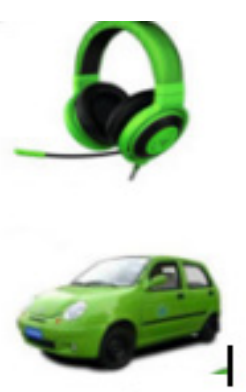

(c)

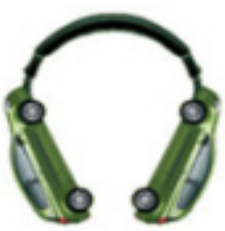

(d)

Figure 8. An example for (S-F-)

Step three: spatial arrangement of metaphorical elements

Pictures are arranged in such an order to ensure participants are aware of the target (product) and the source (referring item): The first one is the picture of the target product, which the advertiser wants to sell the customers. The second is the picture of source item, which is used to represent and modify the product. In the third, the two aforementioned objects are present side by side separately. Its structure is that the target picture is on the above while the source picture is on the below. The fourth picture, which is the focus of the study, combines these two 
together.

Five questions are designed in each set, as follow:

The first question (Q1) is "In this advertisement, a comparison is proposed. To your mind, the advertiser has tried to express that (a) both elements have design in common, (b) both elements have beauty in common, (c) both elements have acuity of vision in common, and (d) no comparison was intended by the advertiser." Only one answer was considered correct". The order of answering options was randomized per participant and per advertisement. Another four questions were used to assess appreciation. Responses were given on a 7-point Likert scale, with answer options ranging from 1 (Strongly disagree) to 7 (Strongly agree). The internal consistency is as following, Q2:"I have a good feeling about this advertisement"; Q3:"I would consider buying this product"; Q4:"I would recommend this product to my friends"; and Q5:"This product could be something for me" was excellent (Cronbach's alpha was 0.96).

By answering these questions, the answers to the following questions can be obtained:

Whether these ads can be understood and liked by the participants.

Whether they have good feelings about this advertisement.

Whether they would consider buying this product.

Whether they would recommend this product to their friends.

Whether this product could be something for them.

As is shown in the survey questionnaire, the first set is an ad about USB (Figure 9):

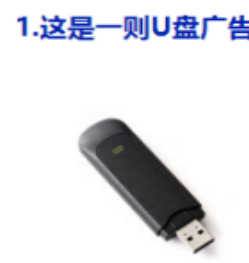

(a)

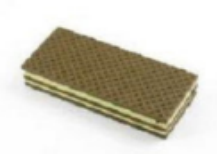

(b)

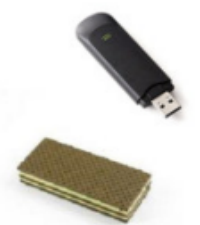

(c)

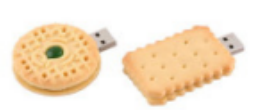

(d)

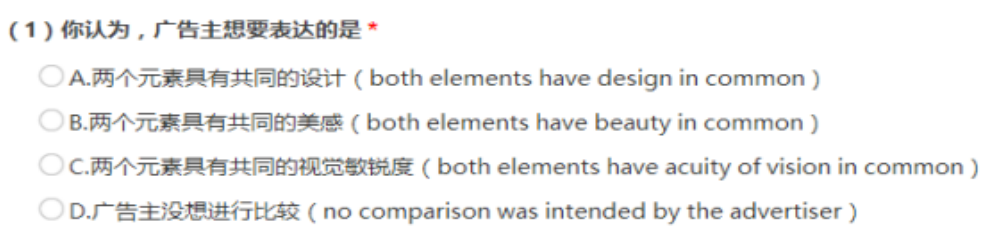

Figure 9. The first set of the questionnaire 
Then, One hundred and one participants answered the questionnaire for data analysis who have different backgrounds of sex, age, education degree, income, etc.

\section{Result and Discussion}

My research uses qualitative and quantitative methods. From the attitude of college students in the ads, I study the effect of visual structure of pictorial metaphors on advertisement attitudes. The pictures of visual metaphor are classified according to their visual structures. At the same time, cross-correlation analysis is conducted.

By analyzing and calculating, the number of pictures in each group is as follows

Those have similar shapes but totally different functions include the first one, fourth one, sixth one, seventh one, ninth one, tenth one, eleventh one, twelfth one, fourteenth one, sixteenth one, nineteenth one, and the twentieth one, totally twelve sets.

Another type is that pictures neither have similar shapes nor similar function such as the third set, the fifth set, and the eighteenth set, totally three sets.

In addition, there are two sets with different shapes but similar functions such as thirteenth set and fifteenth set, totall two sets

Last but not least, there are three sets, which have similar shapes and functions-the second set, the eight set, and the seventeenth set, totally three sets.

The overall mean score of each group was computed for each advertisement, as is shown in Table 2.A higher score indicated greater ad likeability rate.

Table 2. The overall mean score of each group

\begin{tabular}{lllll}
\hline $\begin{array}{l}\text { "S" represents shape } \\
\text { "F" stands for function }\end{array}$ & Q 2 & Q 3 & Q 4 & Q 5 \\
\hline S+F- & 3.74 & 3.81 & 3.47 & 3.72 \\
S-F- & 4.01 & 3.78 & 3.75 & 3.78 \\
S-F+ & 4.155 & 3.89 & 3.87 & 3.85 \\
S+F+ & 4.43 & 4.24 & 4.22 & 4.06 \\
\hline
\end{tabular}

By analyzing, some conclusions can be drawn:

Firstly, the highest score in four questions is always " $\mathrm{S}+\mathrm{F}+$ " (similar shape and similar function).It can be predicted that when source and target have similar forms and function, the product can be easier to be understood. It can be also predicted that customers, when having good feelings to this advertisement of " $\mathrm{S}+\mathrm{F}+$ " (similar shape and similar function) will more possibly consider buying, recommending, and using.

Secondly, the top two is average scores of "S-F+" (different shape and similar function) it can be anticipated that when source and target have different shapes, but similar functions(S-F+), ad liking will be increased for the product. At the same time, compared with the average scores of "S-F-" (different shape and different function) and the average score of "S+F-" (similar shape and different function), the average scores of "S-F+" (different shape and similar function) are higher for these four questions. So, the conclusion can be drawn that when customers are purchasing an item, the most important thing they consider is the practicability.

Thirdly, in a similar way with the previous conclusion, because the average scores of objects with different function are lower than similar function. So, whether the shape is similar or not, if the function is different, customers won't appreciate the picture of products.

Before doing the survey, it was originally anticipated that the object that is fused together would be appreciated. Very much beyond my expectation, the number of people who appreciate the ads doesn't accord with my imagination. Why do people have such attitude towards the ads using visual metaphor?

Besides the studying of twenty groups of pictures, some questions are designed related to the condition of participants including participants' sex, disposable income, ages, and educational status. So, some reasons can be identified as follow:

First of all, the survey can show us that there are many different types of objects such as the microphone, the earphone, the briefcase, and so on. These goods aren't needed by ordinary people. For example, in the Figure 10, the green earphone may not be liked by some conservative people. And in the Figure 11, the briefcase that is combined with meat looks very disgusting. It can't give the customers a good feeling. They may not feel 
comfortable about it.

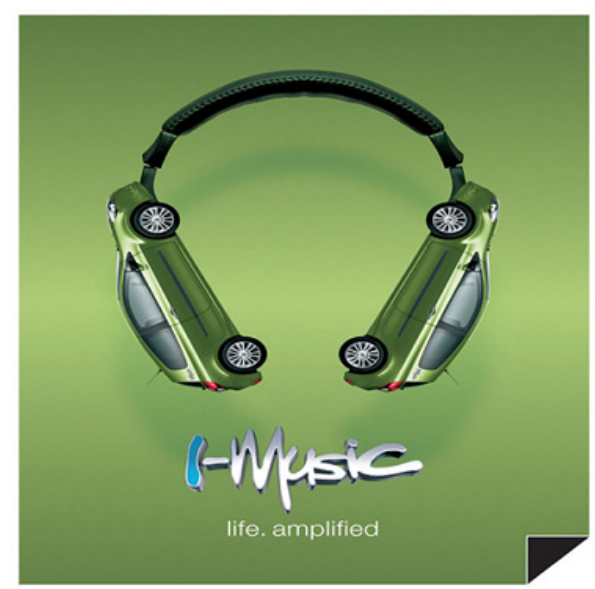

Figure 10

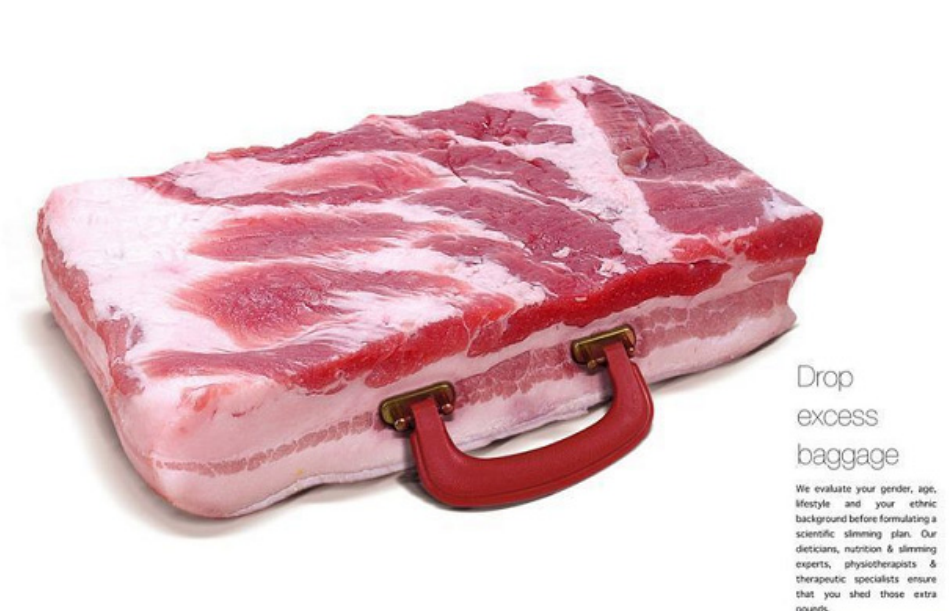

Figure 11

Secondly, these participants have different cultural backgrounds, because of this, people will make different choices when they do the survey. From the final analysis, we find that people with bachelor and master degree like these products in ads more. It is known that college students mainly bachelors and masters, are a very large group of college consumption. They have stable financial support, both from their parents and by themselves. They have broad vision and motivation for buying, which means they have more access to visual metaphors in advertisement. As the result is shown in Figure 12:

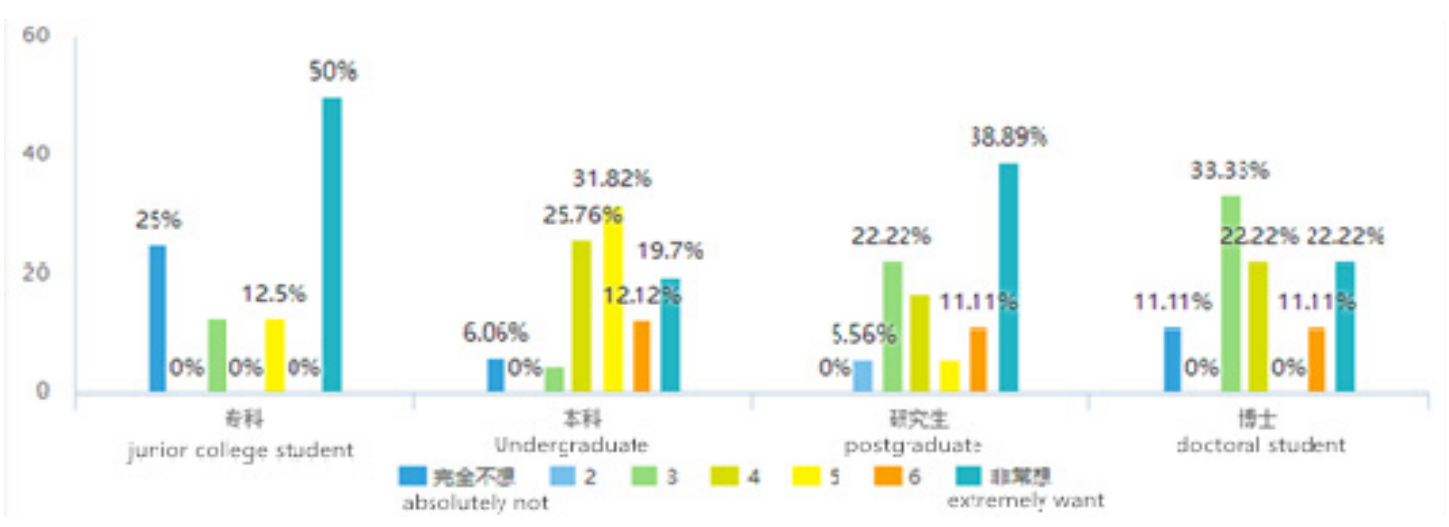

Figure 12. The results of participants with different backgrounds

Thirdly, gender will influence the result of the survey. From the analytical data, we can know female participants like these ads more than men. In the survey, there are many products designed for women. So, we can understand why women have more feelings to these ads. What's more, there are many colorful products.,these products may attract more women to buy. As the result is shown in Figure 13: 


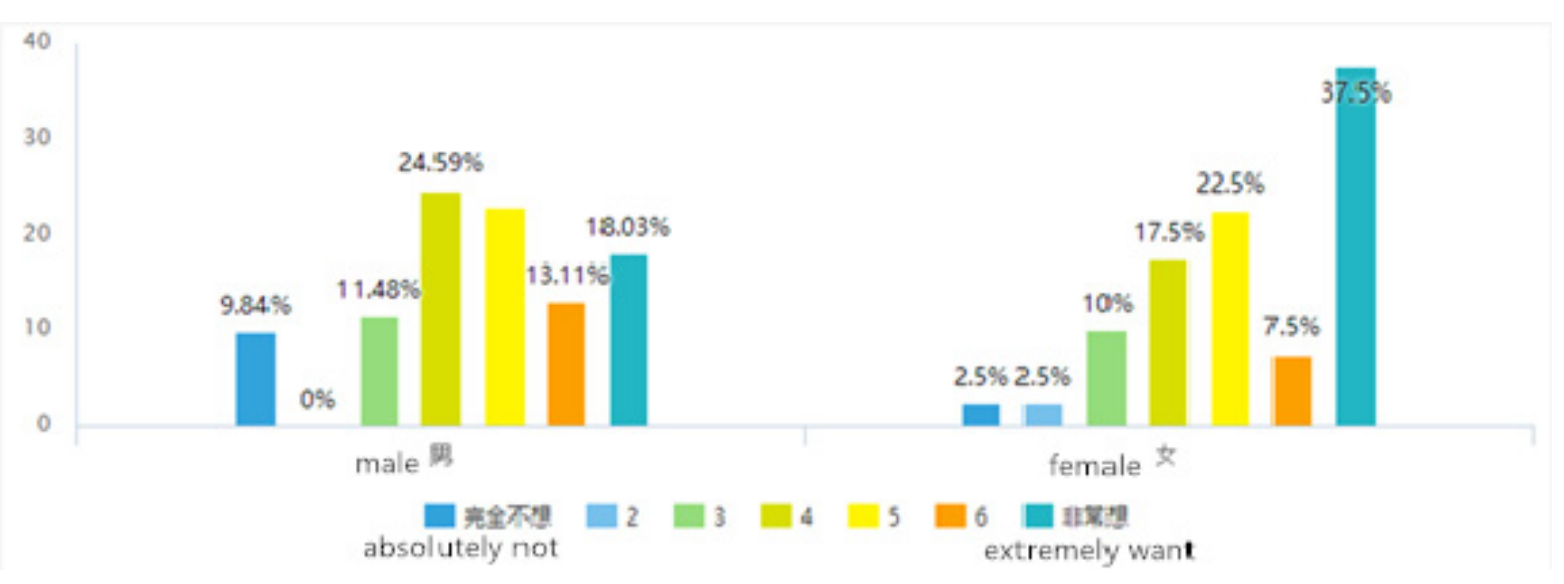

Figure 13. The results of participants with different gender

Fourthly, by analyzing the participants' ages, some conclusions also can be found that people under twenty years have more desire to buy the products in the ads. As the result is shown in Figure 14:

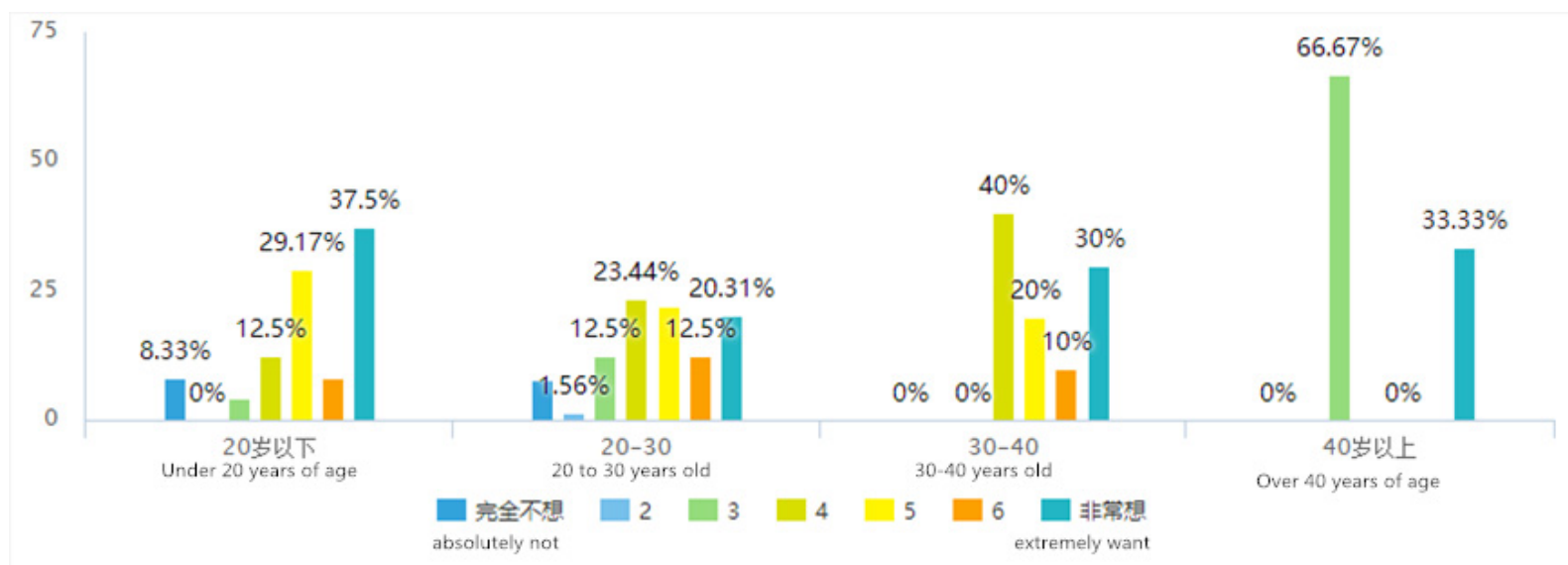

Figure 14. The results of participants with different ages

Why does this situation happen? The object that is fused is very novel for the younger generation. That is to say, those who are young are easier to accept the new things, and vice versa. They always try to experience as much as they can.

Fifthly, by analyzing the participants' disposable income, we can know the people who want to buy the product in the ad are mainly those whose disposable income is between five hundred yuan and one thousand yuan. In other words, the ad liking increases from disposable income of above three thousand to two thousand and three thousand to one thousand and two thousand to five hundred and one thousand. So, we can draw the conclusion that people with low disposable income like the product in the ad more. The low-income group have a desire to possess what they cannot afford. A common product may be an attempt in his or her purchase plan. The result is shown in Figure 15: 


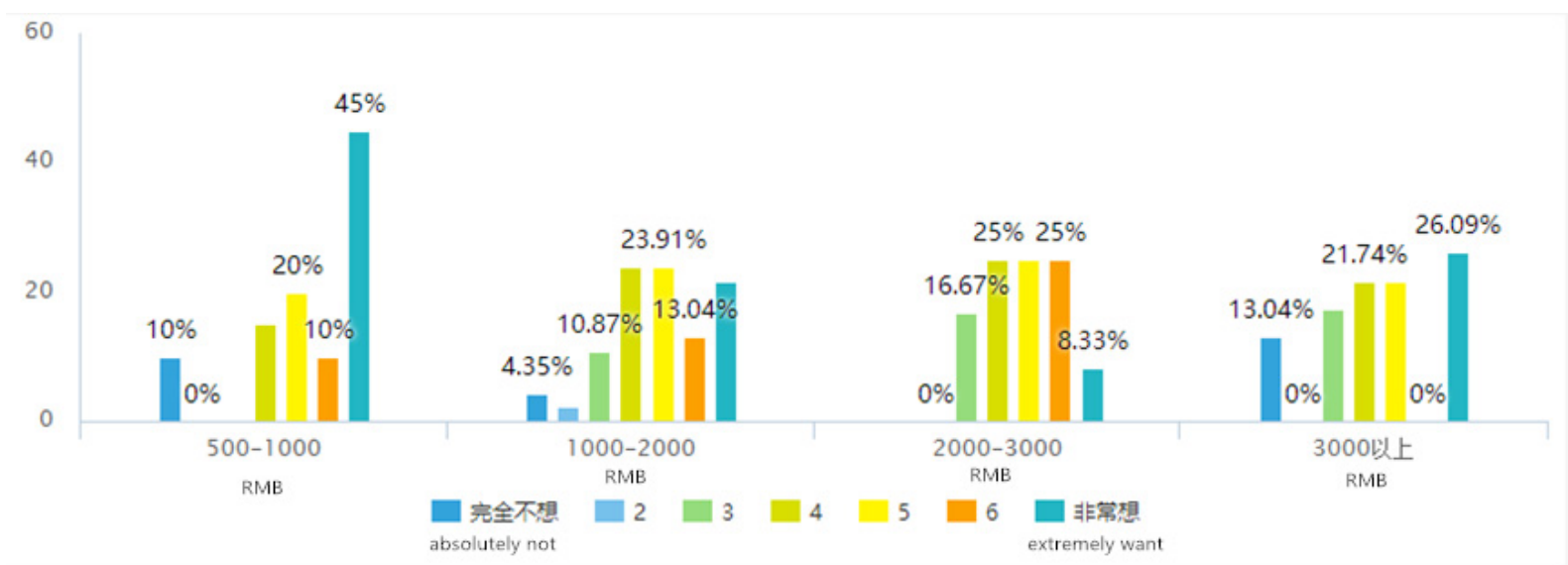

Figure 15. The results of participants with different disposable income

After analyzing the data, we can see the result clearly. In a word, not all the products with visual metaphor are appreciated by customers. That is to say, not all the object that is fused together is popular among the people. Because the survey questionnaire is handed out in China, the conclusion is just drawn that Chinese people don't show so much appreciation to the ads, which use visual metaphor. It occurs to me that Chinese people are likely to be more conservative than foreigners. After all, the consuming behavior is a complicated study, with many factors influencing the attitude, decision and purchase intent.

\section{Conclusions}

Based on the results,we know that the visual pictures that have both similar functions and shapes rank top in all the dimensions examined, followed by those having dissimilar shape but similar function and those having similar shape and dissimilar function. The visual pictures that are dissimilar both in shape and in function are least favored. Demographical analysis was also carried out, showing a higher appreciation for the ad visual metaphors among participants of bachelor's degree and master's degree, females and younger generation. The analysis is consistent with the previous study that the processing of visual metaphors in ads is influenced by many factors, such as age, educational background, types of products, disposable income, gender, and even the relationship between shape and function.

The findings, with specific marketing implication for designing and managing visual metaphors in ads, are valuable for marketers who target at college students, one of the most promising consumer group. This research can help the company find a new market target for the new type of products after analyzing the data. Combining with different background of people, some corresponding marketing strategies can be put forward, such as ad pictures of visual metaphors should be used according to college customers of different background. For the younger ones, novel visual metaphors will work well for the purchase intent. This research takes the ads using visual metaphor as the research object. Chinese college students are regarded as the main research group. At the same time, considering their different background, it can enrich the existing analysis of visual metaphor advertisements. What's more, it also has the value in practice, which can provide empirical supports of the advertising design and campaign as for youth consuming group.

The significance of my research is also in that it examines the effect of visual structure of pictorial metaphors on Chinese participants' advertisement attitudes, especially Chinese college students.

Compared with the pictures similar in shape but not in function, samples of different shape and similar function are far from sufficient in amount. It may affect the result of my study due to the asymmetrical distribution of different types of picture materials. In the meantime, the shape and the function of pictures are paid more attention to in my study. As a matter of fact, there are many other factors, which are likely to have an impact on ad liking of customers. For example, the colors of pictures, the distance between the source and target.So, in the future research, the colors of pictures should become one part of the focus for the study, especially how the perceptual features, conceptual features and color interact between each other. In my questionnaire, there also seem to be some improvements and betterments. For example, the questionnaire I used is self-report. It is not that accurate. Some participants may not express their real feelings, at least not in the questionnaire. So, in my future research, other research methods will be used. For example, psychological experiments will be conducted to further study the processing of visual metaphors, so that a panoramic understanding of the processing of visual 
metaphor, both implicitly and explicitly, will be obtained.

\section{Acknowledgments}

This work was supported by the Fundamental Research Fund for Central Universities (DUT16RW201) and the Social and Scientific Planning Fund of Liaoning (L13DYY035).

\section{References}

Enschot, R., Beckers, C., \& Van Mulken, M. (2010). Rhetorical figures in TV commercials: The occurrence of schemes and tropes and their effects on commercial likeability. Information Design Journal, 18(2), 138-147. https://doi.org/10.1075/idj.18.2.04ens

Forceville, C. (2005). Addressing an audience: Time, place, and genre in Peter Van Straaten's calendar cartoons. Humor, 18(3), 247-278. https://doi.org/10.1515/humr.2005.18.3.247

Gkiouzepas, L., \& Hogg, M. K. (2011). Articulating a Framework of Visual Metaphors in Advertising: A Structural, Conceptual, and Pragmatic Investigation. Journal of Advertising, 40(1), 101-118. https://doi.org/10.2753/JOA0091-3367400107

Hayes, A. F. (2009). Beyond Baron and Kenny: Statistical Mediation Analysis in the New Millennium. Communication Monographs, 76(4), 408-420. https://doi.org/10.1080/03637750903310360

Heckler, S. E., \& Childers, T. L. (1992). The role of expectancy and relevancy in memory for verbal and visual information: What is congruency?. Journal of Consumer Research, 18(4), 475-492. https://doi.org/10.1086/209275

Herr, N. (n.d.). Mediation with Dichotomous Outcomes. December 27, 2013.

Huhmann, B. A., \& Albinsson, P. A. (2012). Does Rhetoric Impact Advertising Effectiveness with Liking Controlled? European Journal of Marketing, 46(11/12), 1476-1500. https://doi.org/10.1108/03090561211259943

Huhmann, B. A., Mothersbaugh, D., \& Franke, G. R. (2002). Rhetorical Figures in Headings and Their Effect on Text Processing: The Moderating Role of Information Relevance and Text Length. IEEE Transactions on Professional Communication, 45(3), 157-169. https://doi.org/10.1109/TPC.2002.801634

Maes, A., \& Schilperoord, J. (2008). Classifying Visual Rhetoric: Conceptual and Structural Devices. In E. F. McQuarrie \& B. J. Phillips (Eds.), Go Figure! New Directions in Advertising Rhetoric (pp. 227-256). New York: M.E. Sharpe.

McQuarrie, E. F., \& Mick, D. G. (1996). Figures of rhetoric in advertising language. Journal of Consumer Research, 11, 424-437. https://doi.org/10.1086/209459

McQuarrie, E. F., \& Mick, D. G. (2003a). The contribution of semiotic and rhetorical perspectives to the explanation of visual persuasion in advertising. In L. Scott \& R. Batra (Eds.), Imagery: A Consumer Response Perspective (pp. 19-21). Mahwah, NJ: Lawrence Erlbaum Associates.

McQuarrie, E. F., \& Mick, D. G. (2003b). Visual and verbal rhetorical figures under directed processing versus incidental exposure to advertising. Journal of Consumer Research, 29, 579-587. https://doi.org/10.1086/346252

McQuarrie, E. F., \& Phillips B. J. (2008). It's not your father's magazine ad: Magnitude and direction of recent changes in advertising style. Journal of Advertising, 37(3), 95-106. https://doi.org/10.2753/JOA0091-3367370307

Meyers, L. S., Gamst, G., \& Guarino, A. (2006). Applied multivariate research: Design and interpretation. Thousand Oaks, CA: Sage Publishers.

Morgan, S. E., \& Reichert, T. (1999). The message is in the metaphor: Assessing the comprehension of metaphors and analogies in advertisements. Journal of Advertising, 28(4), 1-12. https://doi.org/10.1080/00913367.1999.10673592

Mothersbaugh, D. L., Huhmann, B. A., \& Franke, G. R. (2002). Combinatory and Separative Effects of Rhetorical Figures on Consumers Effort and Focus in Ad Processing. Journal of Consumer Research, 28, 589-602. https://doi.org/10.1086/338211

Nordhielm, C. L. (2003). A Levels-of-Processing Model of Advertising Repetition Effects. In L. M. Scott \& R. Batra (Eds.), Persuasive Imagery: A Consumer Response Perspective (pp. 95-104). Mahwah, NJ: Erlbaum. 
Norrick, N. R. (2003). Issues in Conversational Joking. Journal of Pragmatics, 35(9), 1333-59. https://doi.org/10.1016/S0378-2166(02)00180-7

Phillips, B. J., \& McQuarrie, E. (2003). The development, change and transformation of rhetorical style in magazine advertisements 1954-1999. Journal of Advertising, 31(4), 1-13. https://doi.org/10.1080/00913367.2002.10673681

Phillips, B. J., \& McQuarrie, E. (2004). Beyond visual metaphor: A new typology of visual rhetoric in advertising. Marketing Theory, 4, 113-136. https://doi.org/10.1177/1470593104044089

Pieters, R., Wedel, M., \& Batra, R. (2010). The stopping power of advertising: measures and effects of visual complexity. Journal of Marketing, 74, 48-60. https://doi.org/10.1509/jmkg.74.5.48

Toncar, M., \& Munch, J. (2001). Consumer Responses to Tropes in Print Advertising. Journal of Advertising, 30(1), 55-65. https://doi.org/10.1080/00913367.2001.10673631

Utsumi, A. (2007). Interpretive Diversity Explains Metaphor-Simile Distinction. Metaphor and Symbol, 22(4), 291-312. https://doi.org/10.1080/10926480701528071

Van Mulken, M., Le Pair, R., \& Forceville, C. (2010). The impact of perceived complexity, deviation and comprehension on the appreciation of visual metaphor in advertising across three European countries. Journal of Pragmatics, 42(12), 3418-3430. https://doi.org/10.1016/j.pragma.2010.04.030

\section{Copyrights}

Copyright for this article is retained by the author, with first publication rights granted to the journal.

This is an open-access article distributed under the terms and conditions of the Creative Commons Attribution license (http://creativecommons.org/licenses/by/4.0/). 